\title{
Economic evaluation of DNA ploidy analysis vs liquid-based cytology for cervical screening
}

\author{
V T Nghiem ${ }^{1,2}$, K R Davies ${ }^{1}$, J R Beck ${ }^{3}$, M Follen ${ }^{4}$, C MacAulay ${ }^{5}$, M Guillaud ${ }^{5}$ and S B Cantor ${ }^{*}, 1$ \\ ${ }^{1}$ The University of Texas MD Anderson Cancer Center, Department of Health Services Research, 1515 Holcombe Blvd., Houston, \\ TX 77030, USA; ${ }^{2}$ The University of Texas School of Public Health, Division of Management, Policy and Community Health, 1200 \\ Pressler Street, Houston, TX 77030, USA; ${ }^{3}$ Fox Chase Cancer Center, Cancer Prevention and Control Program, 333 Cottman \\ Avenue, Philadelphia, PA 19111, USA; ${ }^{4}$ Brookdale University Hospital \& Medical Center, Department of Obstetrics \& Gynecology, \\ One Brookdale Plaza, Brooklyn, NY 11212, USA and ${ }^{5}$ British Columbia Cancer Research Centre, Integrative Oncology Department, \\ 675 West 10th Avenue, Vancouver, BC V5Z 1L3, Canada
}

Background: DNA ploidy analysis involves automated quantification of chromosomal aneuploidy, a potential marker of progression toward cervical carcinoma. We evaluated the cost-effectiveness of this method for cervical screening, comparing five ploidy strategies (using different numbers of aneuploid cells as cut points) with liquid-based Papanicolaou smear and no screening.

Methods: A state-transition Markov model simulated the natural history of HPV infection and possible progression into cervical neoplasia in a cohort of 12-year-old females. The analysis evaluated cost in 2012 US\$ and effectiveness in quality-adjusted lifeyears (QALYs) from a health-system perspective throughout a lifetime horizon in the US setting. We calculated incremental costeffectiveness ratios (ICERs) to determine the best strategy. The robustness of optimal choices was examined in deterministic and probabilistic sensitivity analyses.

Results: In the base-case analysis, the ploidy 4 cell strategy was cost-effective, yielding an increase of 0.032 QALY and an ICER of $\$ 18264 /$ QALY compared to no screening. For most scenarios in the deterministic sensitivity analysis, the ploidy 4 cell strategy was the only cost-effective strategy. Cost-effectiveness acceptability curves showed that this strategy was more likely to be cost-effective than the Papanicolaou smear.

Conclusion: Compared to the liquid-based Papanicolaou smear, screening with a DNA ploidy strategy appeared less costly and comparably effective.

The successful prevention, diagnosis, and clinical management of cervical cancer depend heavily on early screening. For liquid-based Papanicolaou smear screening to be effective, the clinician must have expertise in distinguishing between tissue or cell abnormalities caused by precancerous lesions and other inflammatory conditions in the cervix (Guillaud et al, 2006). In addition, highly skilled technicians and pathologists must be able to interpret patient specimen slides and produce a definitive diagnosis. Such screening can be particularly challenging in resource-poor settings that lack trained clinicians and pathologists.

An objective method of interpreting cytopathic changes associated with cervical disease, known as DNA ploidy analysis, involves the numerical measurement of DNA content in the nucleus of the cell (Grote et al, 2004; Demirel et al, 2013). Since chromosomal aneuploidy has been significantly associated with progression toward cervical carcinoma, quantification of DNA

*Correspondence: Dr SB Cantor; E-mail: sbcantor@mdanderson.org

Received 30 September 2014; revised 30 January 2015; accepted 15 February 2015; published online 28 April 2015 
aneuploidy may serve as a prognostic marker of disease (Bocking and Nguyen, 2004; Susini et al, 2011). This process can be computerized by machine algorithm to automate diagnosis of cervical lesions and thus implemented in population-based screening. Previous literature has suggested that DNA ploidy analysis is capable of a stand-alone testing method (Sun et al, 2005; Tong et al, 2009).

For automated DNA ploidy analysis to be considered as an alternative for the screening of cervical malignancies, an evaluation with regard to both quality-adjusted life expectancy and costs is needed. This study presents a comparative analysis of DNA ploidy analysis and liquid-based cytology screening in terms of the potential economic costs and clinical benefits of this new technology. Our results may have an impact on the choice of cost-effective strategies for large-scale screening programs.

\section{MATERIALS AND METHODS}

DNA ploidy analysis. By definition, DNA ploidy analysis is a quantitative technique. It is one of the methods used to detect cervical cancer and its precursors. It is performed on Feulgenstained specimens in a semi-automated manner. Unlike liquidbased cytology screening, DNA ploidy analysis is not subject to the retesting of $10 \%$ of normal specimens that is required by Clinical Laboratory Improvement Amendments 1988 regulations (Tabbara and Sidawy, 1996). An abnormal specimen identified by the ploidy method would be equivalent in terms of clinical management to a result of low-grade squamous intraepithelial lesion (LSIL) in the Bethesda system for reporting cytologic results. Thus, either of these abnormal findings - that is, abnormal DNA ploidy or LSIL result for Papanicolaou smear - would be followed up with a diagnostic visit which typically includes colposcopy and biopsy (if required). Treatment, if needed, would occur subsequently.

Five DNA ploidy strategies were examined in this study. In a reported clinical trial, the sensitivity and specificity of the ploidy strategy were measured on the basis of five cut points for the number of aneuploid cells (Table 1) (Guillaud et al, 2006). With the 1 -cell cut point strategy (ploidy 1 cell strategy), the presence of at least one aneuploid cell in a given slide rendered it an abnormal specimen. Similarly, the DNA ploidy cytology at n-cell cut point ( $n$ could be any whole number from 1 to 5 ) designated a specimen as abnormal if $\mathrm{n}$ aneuploid cells were found in a given slide; the terminology 'ploidy n cell strategy' is used for these scenarios.

Comparators. In our study, we assessed the cost-effectiveness of seven strategies: the liquid-based Papanicolaou smear, the five DNA ploidy strategies involving the five cut points described above, and a no screening strategy (as an anchoring strategy). We included 'no screening' as an anchoring strategy only for purposes to determine if DNA ploidy is cost-effective compared to this alternative in the economic evaluation. Our intention was to make a primary comparison of DNA ploidy to the usual care strategy (i.e., Papanicolaou smear screening). We only would make a comparison of DNA ploidy analysis to the anchoring 'no screening' option if it were to be shown that the usual care strategy is not cost-effective compared to DNA ploidy analysis.

The starting age for screening was 21 years, as recommended by the current guidelines from the U.S. Preventive Services Task Force (Agency for Healthcare Research and Quality, 2012). The total cost encompassed four stages in cervical cancer care (screening, diagnosis, detection, and treatment). We evaluated effectiveness in terms of quality-adjusted life-years (QALYs). The comparison was based on the incremental cost-effectiveness ratio (ICER), defined as the additional cost of a strategy divided by its additional effectiveness compared with its next best strategy. We used a willingness-to-pay threshold of \$50 000/QALY (Weinstein, 2008)
Table 1. Parameters for sensitivity analyses

\begin{tabular}{|c|c|c|c|c|}
\hline Parameter & Mean & $\begin{array}{c}\text { Plausible } \\
\text { range }\end{array}$ & Distribution & Source \\
\hline \multicolumn{5}{|l|}{ Costs (2012 US\$) } \\
\hline $\begin{array}{l}\text { Colposcopy } \\
\text { Biopsy }\end{array}$ & $\begin{array}{l}\$ 292 \\
\$ 322\end{array}$ & $\begin{array}{l}\$ 206-\$ 371 \\
\$ 227-\$ 408\end{array}$ & $\begin{array}{l}\text { Log-normal } \\
\text { Log-normal }\end{array}$ & (8) \\
\hline DNA ploidy analysis & $\$ 44$ & $\$ 44-\$ 88$ & $n / a$ & $\begin{array}{c}\text { Assumption } \\
\text { (see text) }\end{array}$ \\
\hline Papanicolaou smear & $\$ 88$ & $\$ 44-\$ 252$ & Gamma & (26) \\
\hline $\begin{array}{l}\text { Treating HSIL } \\
\text { Treating cancer stage I } \\
\text { Treating cancer stage II } \\
\text { Treating cancer stage III } \\
\text { Treating cancer stage IV }\end{array}$ & $\begin{array}{c}\$ 4996 \\
\$ 28914 \\
\$ 44357 \\
\$ 44357 \\
\$ 66006\end{array}$ & $\begin{array}{c}\$ 2268-\$ 6887 \\
\$ 15467-\$ 35962 \\
\$ 19228-\$ 47667 \\
\$ 19228-\$ 47667 \\
\$ 20762-\$ 76213\end{array}$ & $\begin{array}{l}\text { Log-normal } \\
\text { Log-normal } \\
\text { Log-normal } \\
\text { Log-normal } \\
\text { Log-normal }\end{array}$ & (8) \\
\hline \multicolumn{5}{|c|}{ Screening test operating characteristics } \\
\hline $\begin{array}{l}\text { Sensitivity, Papanicolaou } \\
\text { smear } \\
\text { Specificity, Papanicolaou } \\
\text { smear }\end{array}$ & 0.84 & $\begin{array}{l}0.69-0.88 \\
0.77-0.93\end{array}$ & $\begin{array}{l}\text { Beta } \\
\text { Beta }\end{array}$ & (26) \\
\hline Sensitivity, ploidy 1 cell & 0.74 & $0.67-0.79$ & Beta & \\
\hline Specificity, ploidy 1 cell & 0.82 & $0.79-0.83$ & Beta & \\
\hline Sensitivity, ploidy 2 cell & 0.65 & $0.58-0.71$ & Beta & \\
\hline Specificity, ploidy 2 cell & 0.90 & $0.88-0.92$ & Beta & \\
\hline Sensitivity, ploidy 3 cell & 0.59 & $0.52-0.65$ & Beta & (1) \\
\hline Specificity, ploidy 3 cell & 0.93 & $0.92-0.94$ & Beta & \\
\hline Sensitivity, ploidy 4 cell & 0.55 & $0.48-0.61$ & Beta & \\
\hline Specificity, ploidy 4 cell & 0.95 & $0.93-0.96$ & Beta & \\
\hline Sensitivity, ploidy 5 cell & 0.51 & $0.43-0.56$ & Beta & \\
\hline Specificity, ploidy 5 cell & 0.95 & $0.93-0.96$ & Beta & \\
\hline
\end{tabular}

for assessing cost-effectiveness. We discounted the costs and the effectiveness at the same standard rate of $3 \%$ per annum.

Decision-analytic model. We used a previously published statetransition Markov model to simulate the natural history of human papillomavirus (HPV) infection and its potential development into cervical precancer or cancer. This model was first developed by investigators at Duke University (McCrory et al, 1999; Myers et al, 2000; Bergeron et al, 2008) and hereafter will be referred to as the 'Duke model.' A hypothetical cohort of females moved through health states using a cycle length of 1 year. A total of 20 health states were used: Well, Benign Hysterectomy, Undetected HPV, Detected HPV, LSIL, High-Grade Squamous Intraepithelial Lesions (HSIL), Unknown Cancer (stages I-IV), Detected Cancer (stages I-IV), Cancer Survivor (stages I-IV), Death from Cervical Cancer, and Death from Other Causes. From the literature or previous published models of cervical cancer screening, we derived estimates of the regression and progression through the precancerous stages (Eddy, 1990; Fahs et al, 1992), HPV incidence rates adjusted by age (Koutsky et al, 1992; Ho et al, 1998; Moscicki et al, 1998), age-specific prevalence of HPV infection (Hildesheim et al, 1994; Kiviat, 1996; Koutsky, 1997; Ho et al, 1998), and rates of progression and regression of squamous intraepithelial lesions (Syrjanen et al, 1992). The estimation for survival rates for cervical cancer after diagnosis by stage was based on patient care evaluation data obtained from the American College of Surgeons (1990) and patterns-of-care studies (Jones et al, 1995). Having a hysterectomy for benign disease affects the chance of developing cervical cancer; thus, the model included the age-specific hysterectomy rates from the National Hospital Discharge Survey (Lepine et al, 1997) and Maryland discharge data (Kjerulff et al, 1993). The mortality rates for deaths due to other causes were derived by subtracting agespecific cervical cancer mortality rates from the general mortality rates reported in the U.S. life tables (National Center for Health Statistics, 1992). Additionally, the natural history parameters were adjusted to determine the age-specific incidence of cervical cancer in an unscreened population (Gustafsson et al, 1997). 
For the screening and follow-up strategies, a woman would experience a sequential process beginning with either the Papanicolaou smear or ploidy screening, followed by, if warranted, diagnosis with colposcopy and appropriate treatment: loop electrosurgical excision procedure (LEEP) for HSIL, or surgery and radiation for cancer. Key assumptions included the following: (1) $10 \%$ of the normal Papanicolaou smears were retested, (2) women were compliant with clinical treatment recommendations, and (3) after the cancer treatment, a woman could only become a survivor after 5 years, die of cervical cancer, or die of other causes.

Our study made enhancements to the Duke model in order to reflect updated clinical practice. First, we separated colposcopy and biopsy as two individual procedures (no longer a combined process) to allow for the possibility that no biopsy would occur after a normal colposcopy result. This would yield a slight reduction in cost. Second, we incorporated the findings from our work to better reflect the accuracy of colposcopy (Cantor et al, 2008). Third, if a woman had a Papanicolaou smear result of atypical squamous cells of undetermined significance (ASC-US) and a normal colposcopy result, we assumed that two additional follow-up visits over a 1-year period would also be required (Centers for Disease Control and Prevention, 2011; Katki et al, 2011). Fourth, the sensitivity and specificity for all screening and diagnostic tests were updated based on recently published studies (Goldie et al, 2004; Guillaud et al, 2006; Garner, 2014). Fifth, we accounted for the clinical impact of $\mathrm{HPV}$ vaccination in reducing the prevalence and incidence of HPV infection and of progression into cervical neoplasia by a reduction factor. We assumed that as many as $67 \%$ of the women entering the model had been vaccinated. Also, the vaccine helped protect $70 \%$ of the infection cases which were associated with high risk oncogenic types 16 and 18 (Smith et al, 2007; Centers for Disease Control and Prevention, 2013). These resulted in a validated reduction factor of $47 \%$ in the incidence and prevalence of HPV infection (Markowitz et al, 2013) and LSIL.

Effectiveness. We changed the effectiveness measure from life years to QALYs, which incorporates both the quality of life and the survival of the study population (Robberstad, 2005). A value of 1 indicates perfect health and 0 indicates death. This measure was also adjusted by age and health state (Goldie et al, 2004; Elbasha et al, 2007). We assumed that the QALY of a woman after a hysterectomy was equal to that of a cervical cancer survivor. We also incorporated a short-term disutility of 0.01 for treating HSIL.

Costs. Economic inputs in this decision-analytic model were based on the Duke model assumptions (McCrory et al, 1999). These data were derived from both claims and secondary data sources that captured all medical services for screening, diagnosis, and treatment of cervical cancer. The MarketScan database on privately insured individuals (MEDSTAT group) was utilized to estimate the costs in the group of women aged 20-64 years. The costs incurred by the older group $(65+)$ were calculated from Medicare's resource-based relative value system fee schedule, clinical laboratory fee schedule, diagnosis-related group payment rates, and ambulatory surgery center payment rates. Cost-tocharge ratio was used to differentiate the costs from charges associated with hospital and physician services. All costs were transformed to 2012 U.S. dollars using the medical care component of the consumer price index (The Council of Economic Advisers, 2013) (Table 1).

Several cost parameters were modified to fit the structural changes in the model. First, we formulated the cost of a Papanicolaou smear from two published cost estimates, one for normal smears and the other for abnormal smears (Goldie et al, 2004). This single value for the Papanicolaou smear was adjusted by the proportion of normal and abnormal smears in a national survey on women screened for cervical cancer (Datta et al, 2008). Second, we separated the cost of the biopsy and colposcopy procedures, as stated above. A cost fraction to separate these two costs from the former cost (when the biopsy and colposcopy procedures' costs were combined) was derived from the billing data of a sample of patients from our comprehensive cancer center. Third, since the ploidy strategies are not yet practiced in the United States, the cost of the screening procedure with these strategies is unknown. Thus far, the ploidy strategies were reportedly inexpensive in the lab setting (Guillaud et al, 2006; Garner, 2014). We took a micro-costing approach to make an initial estimate of the costs of DNA ploidy analysis, based on a 5-year shelf life for a cytometer, an estimated cost of $\$ 1$ million, the ability to process 15000 to 50000 slides per year at the speed of 40 slides per hour, and inexpensive labor cost for technicians (high school diploma with short training) of $\$ 20$ per hour (Garner, 2014). Then, for purposes of sensitivity analysis, we converted this cost of ploidy into a multiplicative factor as compared to the cost of the Papanicolaou smear, i.e., we estimated that the cost for ploidy analysis was approximately one-half the cost of the Papanicolaou smear procedure. In other words, the ploidy cost factor between any ploidy strategy procedure and the Papanicolaou smear procedure was assumed to be 0.5 . This assumption was varied in the sensitivity analysis.

Analysis. The analysis was conducted from a health-system perspective using a lifetime horizon. Our base-case analysis presented the estimated total cost, total effectiveness, and ICERs for each comparator against its next best alternative when the screening frequency was every 3 years (Agency for Healthcare Research and Quality, 2012) and the ploidy cost factor was 0.5. A screening strategy was deemed as the most cost-effective strategy if it both was cost-effective under the willingness-to-pay threshold of $\$ 50000 / \mathrm{QALY}$ and had the highest effectiveness. Important parameters were chosen for the sensitivity analysis based on their potential impact on the assessment of cost-effectiveness (Table 1). In a one-way sensitivity analysis, we individually varied the selected parameters throughout their plausible ranges when the screening frequency was every 3 years and the ploidy cost factor was 0.5. A two-way sensitivity analysis investigated the cost-effectiveness rankings among comparators when the frequency of screening was varied from every 1 year, every 2 years, every 3 years, every 5 years, and every 10 years while the ploidy cost factor was varied from 0.5 , 0.75 , and 1.0. Although screening every 3 years is the standard, multiple intervals were included in the analysis to reflect the practice (some may screen more or less frequently than others). We ran the probabilistic sensitivity analysis with 10000 iterations to examine the robustness of the total cost and total effectiveness of all seven strategies. The ploidy strategy that was most likely to be the most cost-effective (determined by the deterministic sensitivity analysis) was chosen as the best ploidy strategy. We then evaluated the cost-effectiveness between the best ploidy strategy and the Papanicolaou smear in a cost-effectiveness plane. Cost-effectiveness acceptability curves were used to compare all of the seven strategies across a wide range of willingness-to-pay thresholds. The probabilistic sensitivity analysis was conducted under the following assumptions: (1) probability parameters were fitted with beta distributions and cost parameters with either log-normal distributions or gamma distributions; (2) for beta and gamma distributions, the standard deviation was estimated as one-fourth of the plausible range; (3) all the distributions were independent; (4) the cost of the Papanicolaou smear was stochastically varied in a gamma distribution, and the cost of the ploidy strategy was always set as one-half of the cost of the Papanicolaou smear in the base-case. The model was programmed and the analysis was performed in TreeAge Pro 2014 software (TreeAge Software Inc., Williamstown, MA, USA). 


\section{RESULTS}

Base-case analysis. In the base-case analysis, the ploidy 4 cell strategy was the only cost-effective screening strategy under the willingness-to-pay threshold of $\$ 50000 / \mathrm{QALY}$. In comparison to the anchoring no screening strategy, screening with the ploidy 4 cell strategy increased the quality-adjusted life expectancy by 0.032 QALY and yielded an ICER of \$18 264/QALY. The Papanicolaou smear strategy was the most expensive; in addition, with a much higher ICER ( $\$ 192502 /$ QALY), the Papanicolaou smear strategy was found to be not cost-effective (Table 2).

Deterministic sensitivity analysis. We used the screening frequency of every 3 years and the ploidy cost factor being 0.5 (as the base-case) for the one-way sensitivity analyses. For most of these analyses, the ploidy 4 cell strategy was found to be the only costeffective strategy, with ICERs ranging from \$15151 to approximately $\$ 40000$ per QALY. In some extreme cases in which the specificity of ploidy 4 cell was at the lower bound or the specificity of ploidy 5 cell was at the upper bound, ploidy 5 cell became the only cost-effective strategy. The Papanicolaou smear was not cost-effective, with high ICERs of approximately \$200 000/QALY. A one-way sensitivity analysis with the ploidy cost factor of 0.75 revealed that ploidy 4 cell was the only cost-effective strategy most of the time. Exceptionally, if the specificity of the Papanicolaou smear was as high as its upper bound, the Papanicolaou smear was the most cost-effective strategy (data not shown).

A two-way sensitivity analysis was implemented by varying the frequency of screening (every 1, 2, 3, 5, and 10 years) and the ploidy cost factor $(0.50,0.75$, and 1.0$)$. For all screening strategies, the ICERs were smaller when the screening was done less frequently. Further, increasing the ploidy cost factor resulted in increases in the ICERs. For example, at the same screening frequency of every 2 years, the ICERs for the ploidy 4 cell strategy increased from $\$ 24161$ to $\$ 30699$ per QALY when the ploidy cost factor changed from 0.50 to 0.75 and to $\$ 37238$ when the ploidy cost factor changed to 1.0. Table 3 presents the most cost-effective screening strategies for the fifteen scenarios developed by changing the screening frequency and the ploidy cost factor. In ten of the twelve scenarios (excluding screening every 10 years), the ploidy 4 cell was the only cost-effective strategy in all scenarios, and it produced ICERs ranging from $\$ 13157$ to $\$ 42655$. When the screening frequency was every 1 year (no longer the clinical recommendation) and the ploidy cost factor was either 0.75 or 1.0 , none of the screening strategies was found to be cost-effective using the \$50000/QALY threshold. The Papanicolaou smear strategy produced limited additional effectiveness with much greater cost, yielding ICERs as large as $\$ 463506$. The Papanicolaou smear became the next best strategy after the ploidy 4 cell strategy in only three of the twelve scenarios. Of interest, the Papanicolaou smear strategy would be the most cost-effective if the screening frequency was every 10 years. However, with that frequency, the ploidy 4 cell strategy was cost-effective with ICERs less than $\$ 16000 /$ QALY (data not shown).

Based on the results described above, the ploidy 4 cell strategy was selected as the best ploidy strategy in the deterministic sensitivity analysis.

Probabilistic sensitivity analysis. In the probabilistic sensitivity analysis, the cost and the effectiveness of the seven strategies were plotted (Figure 1). The expected cost varied in increments of thousands of U.S. dollars; however, the variation in the expected effectiveness was as small as hundredths of a QALY. The seven strategies were positioned from left to right in increasing order of screening test sensitivities. The no screening strategy was the farthest to the left and apart from the other six strategies because it had the least effectiveness by a large margin. This effectiveness also remained unchanged because it did not involve any variables included in the sensitivity analysis. The Papanicolaou smear strategy was the farthest to the right since it gained the most effectiveness. It also had the widest variation both in cost and effectiveness. The cost of the Papanicolaou smear was the key driver of this strategy's total cost variation. The largest plausible range of the sensitivity and specificity (compared with the five ploidy strategies) of the Papanicolaou smear resulted in the most extended spread for this strategy on the effectiveness axis. The ploidy strategies and the no screening strategy had comparable cost ranges because they were influenced by the same set of cost variables (excluding the screening procedure cost). The costversus-effectiveness scatter plots for the five ploidy strategies were located next to each other and partially overlapped, since their screening test characteristics were similar.

A comparison of the Papanicolaou smear strategy to the ploidy 4 cell strategy (the best ploidy strategy determined by the deterministic sensitivity analysis) yielded ICERs primarily in the northeast quadrant of the cost-effectiveness plane (Figure 2). These ICERs had a probability of 0.91 of being larger than the willingness-to-pay threshold.

Based on the proportion of iterations for which each strategy had the highest net benefit, we investigated the probabilities of a strategy being cost-effective across a wide range of willingnessto-pay thresholds, from $\$ 0$ to $\$ 150000$ per QALY, using costeffectiveness acceptability curves for all seven strategies (Figure 3 ). The ploidy 4 cell strategy had the highest probability of being cost effective among the five ploidy strategies if the willingness-to-pay threshold was less than $\$ 150000 / \mathrm{Q} A L Y$. The ploidy 4 cell strategy had a higher probability of being cost-effective than the Papanicolaou smear at the willingness-to-pay threshold of $\$ 50000 /$ QALY and at all other larger thresholds up to $\$ 120000$ /

Table 2. Discounted costs, discounted quality-adjusted life expectancy (QALYs), and incremental cost-effectiveness ratios (ICERs) for the base-case analysis (screening every 3 years)

\begin{tabular}{|l|c|c|c|c|c|c|c|}
\hline Strategy & $\begin{array}{c}\text { (Sensitivity, } \\
\text { specificity) }\end{array}$ & Cost $(\$)$ & Incr. cost $(\$)$ & Eff. (QALYs) & Incr. eff. (QALYs) & ICER (\$/QALY) & Notes \\
\hline No screening & & $\$ 189$ & & 24.685 & & & \\
\hline Ploidy 5 cell & $(0.51 ; 0.95)$ & $\$ 763$ & $\$ 574$ & 24.715 & 0.030 & $\$ 18821$ & Extended dominance \\
\hline Ploidy 4 cell & $(0.55 ; 0.95)$ & $\$ 767$ & $\$ 577$ & 24.716 & 0.032 & $\$ 18264$ & a \\
\hline Ploidy 3 cell & $(0.59 ; 0.93)$ & $\$ 878$ & $\$ 110$ & 24.717 & 0.001 & $\$ 132803$ & \\
\hline Ploidy 2 cell & $(0.65 ; 0.90)$ & $\$ 1044$ & $\$ 167$ & 24.718 & 0.001 & $\$ 148863$ & Extended dominance \\
\hline Ploidy 1 cell & $(0.74 ; 0.82)$ & $\$ 1482$ & $\$ 438$ & 24.719 & 0.001 & $\$ 418436$ & b \\
\hline Papanicolaou smear & $(0.84 ; 0.88)$ & $\$ 1758$ & $\$ 276$ & 24.722 & 0.004 & $\$ 192502$ & \\
\hline $\begin{array}{l}\text { Abbreviations: Eff= effectiveness; Incr= incremental. } \\
\text { a'Was compared with the no screening strategy because the ploidy } 5 \text { cell strategy was dominated in an extended sense. }\end{array}$ \\
b'Was compared with the ploidy 2 cell strategy because the ploidy 1 cell strategy was dominated in an extended sense.
\end{tabular}


Table 3. The most cost-effective strategy, its next best alternative, and the Papanicolaou smear with the ICERs in a two-way sensitivity analysis with respect to screening frequency and ploidy cost factor

\begin{tabular}{|c|c|c|c|c|c|c|}
\hline \multirow[b]{2}{*}{$\begin{array}{l}\text { Screening } \\
\text { frequency }\end{array}$} & \multicolumn{2}{|c|}{ Ploidy cost factor $=0.5$} & \multicolumn{2}{|c|}{ Ploidy cost factor $=0.75$} & \multicolumn{2}{|c|}{ Ploidy cost factor $=1.0$} \\
\hline & $\begin{array}{l}\text { Screening } \\
\text { strategy }\end{array}$ & Strategy, ICER & $\begin{array}{l}\text { Screening } \\
\text { strategy }\end{array}$ & Strategy, ICER & $\begin{array}{c}\text { Screening } \\
\text { strategy }\end{array}$ & Strategy, ICER \\
\hline Screening every 1 year & $\begin{array}{l}\text { Most cost-effective } \\
\text { Next best alternative } \\
\text { Papanicolaou smear }\end{array}$ & $\begin{array}{l}\text { Ploidy } 4 \text { cell, } \$ 42655 \\
\text { Ploidy } 3 \text { cell, more than } 1 \mathrm{M}^{\mathrm{b}} \\
\text { Dominated }\end{array}$ & $\begin{array}{l}\text { Most cost-effective } \\
\text { Next best alternative } \\
\text { Papanicolaou smear }\end{array}$ & $\begin{array}{l}\text { Ploidy } 4 \text { cell, } \$ 54008 \\
\text { Ploidy } 3 \text { cell, more than } 1 \mathrm{M} \\
\text { Dominated }\end{array}$ & $\begin{array}{l}\text { Most cost-effective } \\
\text { Next best alternative } \\
\text { Papanicolaou smear }\end{array}$ & $\begin{array}{l}\text { Ploidy } 4 \text { cell, } \$ 65361 \\
\text { Ploidy } 3 \text { cell, more than } 1 \mathrm{M} \\
\text { Dominated }\end{array}$ \\
\hline Screening every 2 years & $\begin{array}{l}\text { Most cost-effective } \\
\text { Next best alternative } \\
\text { Papanicolaou smear }\end{array}$ & $\begin{array}{l}\text { Ploidy } 4 \text { cell, } \$ 24161 \\
\text { Ploidy } 3 \text { cell, } \$ 284249 \\
\$ 463506\end{array}$ & $\begin{array}{l}\text { Most cost-effective } \\
\text { Next best alternative } \\
\text { Papanicolaou smear }\end{array}$ & $\begin{array}{l}\text { Ploidy } 4 \text { cell, } \$ 30699 \\
\text { Ploidy } 3 \text { cell, } \$ 297995 \\
\$ 351416\end{array}$ & $\begin{array}{l}\text { Most cost-effective } \\
\text { Next best alternative } \\
\text { Papanicolaou smear }\end{array}$ & $\begin{array}{l}\text { Ploidy } 4 \text { cell, } \$ 37238 \\
\text { Papanicolaou smear, } \$ 276891 \\
\$ 276891\end{array}$ \\
\hline Screening every 3 years & $\begin{array}{l}\text { Most cost-effective } \\
\text { Next best alternative } \\
\text { Papanicolaou smear }\end{array}$ & $\begin{array}{l}\text { Ploidy } 4 \text { cell, } \$ 18824 \\
\text { Ploidy } 3 \text { cell, } \$ 132803 \\
\$ 192502\end{array}$ & $\begin{array}{l}\text { Most cost-effective } \\
\text { Next best alternative } \\
\text { Papanicolaou smear }\end{array}$ & $\begin{array}{l}\text { Ploidy } 4 \text { cell, } \$ 23270 \\
\text { Ploidy } 3 \text { cell, } \$ 139252 \\
\$ 148501\end{array}$ & $\begin{array}{l}\text { Most cost-effective } \\
\text { Next best alternative } \\
\text { Papanicolaou smear }\end{array}$ & $\begin{array}{l}\text { Ploidy } 4 \text { cell, } \$ 28277 \\
\text { Papanicolaou smear, } \$ 119198 \\
\$ 119198\end{array}$ \\
\hline Screening every 5 years & $\begin{array}{l}\text { Most cost-effective } \\
\text { Next best alternative } \\
\text { Papanicolaou smear }\end{array}$ & $\begin{array}{l}\text { Ploidy } 4 \text { cell, } \$ 13157 \\
\text { Ploidy } 3 \text { cell, } \$ 66184 \\
\$ 92403\end{array}$ & $\begin{array}{l}\text { Most cost-effective } \\
\text { Next best alternative } \\
\text { Papanicolaou smear }\end{array}$ & $\begin{array}{l}\text { Ploidy } 4 \text { cell, } \$ 16916 \\
\text { Ploidy } 3 \text { cell, } \$ 69444 \\
\$ 71278\end{array}$ & $\begin{array}{l}\text { Most cost-effective } \\
\text { Next best alternative } \\
\text { Papanicolaou smear }\end{array}$ & $\begin{array}{l}\text { Ploidy } 4 \text { cell, } \$ 20674 \\
\text { Papanicolaou smear, } \$ 57543 \\
\$ 57543\end{array}$ \\
\hline Screening every 10 years & $\begin{array}{l}\text { Most cost-effective } \\
\text { Next best alternative } \\
\text { Papanicolaou smear }\end{array}$ & $\begin{array}{l}\text { Papanicolaou smear, } \$ 47176 \\
\text { n/a } \\
\$ 47176\end{array}$ & $\begin{array}{l}\text { Most cost-effective } \\
\text { Next best alternative } \\
\text { Papanicolaou smear }\end{array}$ & $\begin{array}{l}\text { Papanicolaou smear, } \$ 36727 \\
\text { n/a } \\
\$ 36727\end{array}$ & $\begin{array}{l}\text { Most cost-effective } \\
\text { Next best alternative } \\
\text { Papanicolaou smear }\end{array}$ & $\begin{array}{l}\text { Papanicolaou smear, } \$ 29655 \\
\text { n/a } \\
\$ 29655\end{array}$ \\
\hline
\end{tabular}

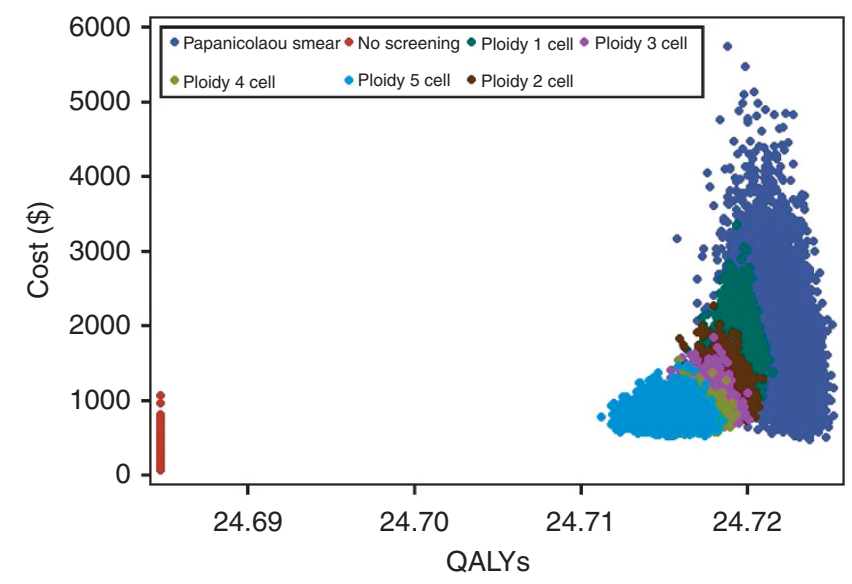

Figure 1. Scatter plot of expected cost and quality-adjusted life expectancy for all seven strategies.

QALY. The cost-effectiveness of the ploidy 4 cell strategy was inferior to the Papanicolaou smear only when the willingness-topay increased beyond \$120000/QALY, which may be considered as impractical in most US settings.

\section{DISCUSSION}

Our study - which is, as far as we know based on a MEDLINE literature review, the first economic analysis of DNA ploidy analysis for cervical cancer screening-shows that DNA ploidy analysis is less expensive than and similarly effective as liquidbased Papanicolaou smear screening. Within the baseline model, DNA ploidy analysis using the ploidy 4 cell strategy was demonstrated as cost-effective using the willingness-to-pay threshold of $\$ 50000 / \mathrm{Q} A L Y$. This result was supported by the probabilistic sensitivity analysis, in which the ploidy 4 cell strategy had the highest probability of being cost-effective under the aforementioned threshold. The sensitivity analysis also revealed that some of the other ploidy strategies (i.e., the ploidy 5 cell and ploidy 3 cell strategies) had the potential to be cost-

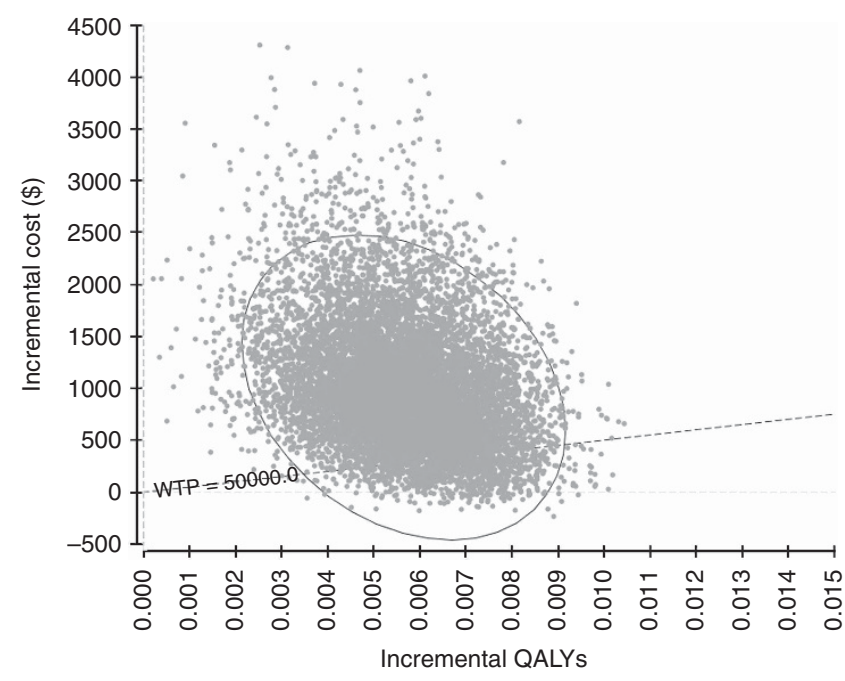

Figure 2. Cost-effectiveness plane for a comparison between the Papanicolaou smear and ploidy 4 cell strategies. Abbreviation: WTP $=$ willingness-to-pay.

effective if the diagnostic characteristics (i.e., sensitivity and specificity) improved. These results are supportive of previous studies showing that DNA ploidy analysis (Guillaud et al, 2006) or semi-automated cytology (Kitchener et al, 2011) achieves diagnostic characteristics comparable to those of the liquid-based Papanicolaou smear.

Models can guide decision-making regarding the use of new technology. In this study, we have also applied decision analysis and cost-effectiveness analysis to determine the optimal cut point for a screening test. As shown by our previous work (Cantor et al, 1999), diagnostic cut points should be determined by conducting receiver operating characteristic (ROC) curve analysis; the optimal cutoff value for a diagnostic test can be found on the ROC curve where the slope of the curve is equal to $(C / B) \times(1$ $\mathrm{p}[\mathrm{D}]) / \mathrm{p}[\mathrm{D}]$, where $\mathrm{p}[\mathrm{D}]$ is the disease prevalence and $\mathrm{C} / \mathrm{B}$ is the ratio of the net costs of treating nondiseased individuals to the net benefits of treating diseased individuals. Therefore, cut points are identified by an arbitrary decision, or using assumptions that do not necessarily hold true, e.g., that the burden of a false-positive test is the same as the burden of a false-negative test. For instance, 


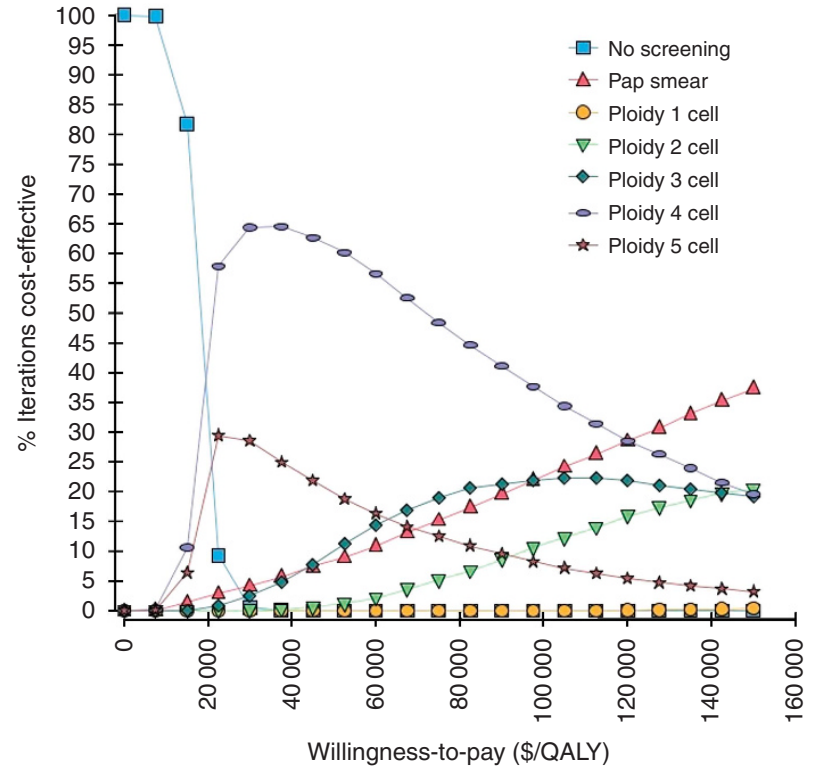

Figure 3. Cost-effectiveness acceptability curves comparing seven strategies: no screening, Papanicolaou (Pap) smear, and the five ploidy strategies. Curves indicate the probability that the given strategy is cost-effective at a given willingness-to-pay.

the comparative evaluation between DNA ploidy analysis, HPV testing, and conventional cytology presented by Guillaud et al (Guillaud et al, 2006) used a ploidy 3 cell strategy, which was chosen as a midpoint strategy. While the results showed that DNA ploidy analysis performed comparably to conventional screening, the ploidy 3 cell strategy was chosen somewhat arbitrarily. By methodically comparing several ploidy strategies along with the liquid-based Papanicolaou smear, our decision model revealed that the ploidy 4 cell strategy results in a costeffective screening strategy. Additionally, inherent of an appropriately designed decision analysis or cost-effectiveness analysis, our model incorporates the consequences of undertreatment (missing a case of precancer or cancer) or overtreatment (incorporating costs and some burden of treatment).

This study has limitations, including that to conduct our analyses, we adapted a cervical cancer screening model that was first published 15 years ago (Myers et al, 2000). However, it should be recognized that we enhanced the model in several important ways (e.g., incorporating utilities and diagnostic protocols), described above, to better reflect the current standard of clinical care. At this point, we did not evaluate other screening strategies, such as triage methods using Ki67 in conjunction with HPV tests ( $\mathrm{Li}$ et al, 2012). The model was kept simple to focus on DNA ploidy analysis, comparing it with two alternatives: First, although it is not an ethically viable clinical strategy, a no screening alternative was included in the analysis as benchmark for evaluating potential cost-effective strategies and for the purpose of validity check. Second, we compared DNA ploidy analysis with the standard of care, the Papanicolaou smear. This liquid-based screening standard in the United States is well established, and health care decision-making operates under a paradigm in which the alternative that provides maximum health benefits for a given level of resources is chosen (Sloan, 1995). Thus, it would be difficult to implement a new program that offers a lower health benefit in spite of having lower costs (Kent et al, 2004; Kitchener et al, 2011). Nevertheless, as lowering the cost of health care has taken greater priority in recent years, DNA ploidy analysis may emerge as a reasonable alternative (Sun et al, 2005). DNA ploidy analysis may be more feasible in low-resource settings. We included less frequent screening (i.e., every 5 or 10 years) as an initial exploration of how well DNA ploidy might work in low-resource settings. However, the applicability of our results in low-resource settings cannot fully be determined without more specific information about the epidemiology of cervical cancer and its treatment in that particular setting.

In conclusion, we have shown that when DNA ploidy analysis is compared with liquid-based Papanicolaou screening, DNA ploidy analysis is a cost-effective alternative. Cervical cancer is the leading cause of cancer deaths in lower-resource settings (Arbyn et al, 2011). Preventative screening programs centered on liquid-based cytology require a comprehensive and costly infrastructure. Thus, DNA ploidy analysis is a promising alternative in health care environments in which inexpensive and semi-automated services are essential.

\section{ACKNOWLEDGEMENTS}

The authors wish to thank Sunita C. Patterson for editorial contributions and Jennifer M. Gatilao for administrative assistance. This study was funded in part by grant numbers P01 CA082710, P30 CA006927, and CA016672 from the National Cancer Institute/National Institutes of Health (NCI/NIH). Van T. Nghiem was supported by a Predoctoral Fellowship, The University of Texas School of Public Health, Cancer Education and Career Development Program - NCI/NIH Grant R25 CA57712.

\section{DISCLAIMER}

The content is solely the responsibility of the authors and does not necessarily represent the official views of the National Cancer Institute or the National Institutes of Health. Findings from this study were presented, in part, at 36th Annual North American Meeting of the Society for Medical Decision Making in October 2014.

\section{CONFLICT OF INTEREST}

The authors declare no conflict of interest.

\section{REFERENCES}

Agency for Healthcare Research and Quality (2012) Screening for Cervical Cancer: Clinical Summary of U.S. Preventive Services Task Force Recommendation. AHRQ Publication No. 11-05156-EF-3, March 2012.

Arbyn M, Castellsague X, de Sanjose S, Bruni L, Saraiya M, Bray F, Ferlay J (2011) Worldwide burden of cervical cancer in 2008. Ann Oncol 22(12): 2675-2686.

Bergeron C, Largeron N, McAllister R, Mathevet P, Remy V (2008) Costeffectiveness analysis of the introduction of a quadrivalent human papillomavirus vaccine in France. Int J Technol Assess Health Care 24(1): 10-19.

Bocking A, Nguyen VQ (2004) Diagnostic and prognostic use of DNA image cytometry in cervical squamous intraepithelial lesions and invasive carcinoma. Cancer 102(1): 41-54.

Cantor SB, Cardenas-Turanzas M, Cox DD, Atkinson EN, Nogueras-Gonzalez GM, Beck JR, Follen M, Benedet JL (2008) Accuracy of colposcopy in the diagnostic setting compared with the screening setting. Obstet Gynecol 111(1): 7-14.

Cantor SB, Sun CC, Tortolero-Luna G, Richards-Kortum R, Follen M (1999) A comparison of $\mathrm{C} / \mathrm{B}$ ratios from studies using receiver operating characteristic curve analysis. J Clin Epidemiol 52(9): 885-892. 
Centers for Disease Control and Prevention (2011) STD Treatment Guidelines, 2010. MMWR 59(No. RR-12): 76-76 Vol. 2014.

Centers for Disease Control and Prevention (2013) National and state vaccination coverage among adolescents aged 13-17 years - United States, 2012. MMWR 62(34): 685-693.

Datta SD, Koutsky LA, Ratelle S, Unger ER, Shlay J, McClain T, Weaver B, Kerndt P, Zenilman J, Hagensee M, Suhr CJ, Weinstock H (2008) Human papillomavirus infection and cervical cytology in women screened for cervical cancer in the United States, 2003-2005. Ann Intern Med 148(7): 493-500.

Demirel D, Akyurek N, Ramzy I (2013) Diagnostic and prognostic significance of image cytometric DNA ploidy measurement in cytological samples of cervical squamous intraepithelial lesions. Cytopathology 24(2): 105-112.

Eddy DM (1990) Screening for cervical cancer. Ann Intern Med 113(3): 214-226.

Elbasha EH, Dasbach EJ, Insinga RP (2007) Model for assessing human papillomavirus vaccination strategies. Emerg Infect Dis 13(1): 28-41.

Fahs MC, Mandelblatt J, Schechter C, Muller C (1992) Cost effectiveness of cervical cancer screening for the elderly. Ann Intern Med 117(6): 520-527.

Garner D (2014) Clinical application of DNA ploidy to cervical cancer screening: A review. World J Clin Oncol 5(5): 931-965.

Goldie SJ, Kohli M, Grima D, Weinstein MC, Wright TC, Bosch FX, Franco E (2004) Projected clinical benefits and cost-effectiveness of a human papillomavirus 16/18 vaccine. J Natl Cancer Inst 96(8): 604-615.

Grote HJ, Nguyen HV, Leick AG, Bocking A (2004) Identification of progressive cervical epithelial cell abnormalities using DNA image cytometry. Cancer 102(6): 373-379.

Guillaud M, Benedet JL, Cantor SB, Staerkel G, Follen M, MacAulay C (2006) DNA ploidy compared with human papilloma virus testing (Hybrid Capture II) and conventional cervical cytology as a primary screening test for cervical high-grade lesions and cancer in 1555 patients with biopsy confirmation. Cancer 107(2): 309-318.

Gustafsson L, Ponten J, Bergstrom R, Adami HO (1997) International incidence rates of invasive cervical cancer before cytological screening. Int J Cancer 71(2): 159-165.

Hildesheim A, Schiffman MH, Gravitt PE, Glass AG, Greer CE, Zhang T, Scott DR, Rush BB, Lawler P, Sherman ME, Kurman RJ, Manos MM (1994) Persistence of type-specific human papillomavirus infection among cytologically normal women. J Infect Dis 169(2): 235-240.

Ho GY, Bierman R, Beardsley L, Chang CJ, Burk RD (1998) Natural history of cervicovaginal papillomavirus infection in young women. $N$ Engl J Med 338(7): 423-428.

Jones WB, Shingleton HM, Russell A, Chmiel JS, Fremgen AM, Clive RE, Zuber-Ocwieja KE, Winchester DP (1995) Patterns of care for invasive cervical cancer. Results of a national survey of 1984 and 1990. Cancer 76(10 Suppl): 1934-1947.

Katki HA, Kinney WK, Fetterman B, Lorey T, Poitras NE, Cheung L, Demuth F, Schiffman M, Wacholder S, Castle PE (2011) Cervical cancer risk for women undergoing concurrent testing for human papillomavirus and cervical cytology: a population-based study in routine clinical practice. Lancet Oncol 12(7): 663-672.

Kent DM, Fendrick AM, Langa KM (2004) New and dis-improved: on the evaluation and use of less effective, less expensive medical interventions. Med Decis Making 24(3): 281-286.

Kitchener HC, Blanks R, Cubie H, Desai M, Dunn G, Legood R, Gray A, Sadique Z, Moss S (2011) MAVARIC - a comparison of automationassisted and manual cervical screening: a randomised controlled trial. Health Technol Assess 15(3): iii-iv, ix-xi, 1-170.

Kiviat N (1996) Natural history of cervical neoplasia: overview and update. Am J Obstet Gynecol 175(4 Pt 2): 1099-1104.

Kjerulff KH, Guzinski GM, Langenberg PW, Stolley PD, Moye NE, Kazandjian VA (1993) Hysterectomy and race. Obstet Gynecol 82(5): 757-764.

Koutsky L (1997) Epidemiology of genital human papillomavirus infection. Am J Med 102(5A): 3-8.

Koutsky LA, Holmes KK, Critchlow CW, Stevens CE, Paavonen J, Beckmann AM, DeRouen TA, Galloway DA, Vernon D, Kiviat NB (1992) A cohort study of the risk of cervical intraepithelial neoplasia grade 2 or 3 in relation to papillomavirus infection. N Engl J Med 327(18): 1272-1278.
Lepine LA, Hillis SD, Marchbanks PA, Koonin LM, Morrow B, Kieke BA, Wilcox LS (1997) Hysterectomy surveillance-United States, 1980-1993. MMWR CDC Surveill Summ 46(4): 1-15.

Li G, Guillaud M, Follen M, MacAulay C (2012) Double staining cytologic samples with quantitative Feulgen-thionin and anti-Ki-67 immunocytochemistry as a method of distinguishing cells with abnormal DNA content from normal cycling cells. Anal Quant Cytopathol Histpathol 34(5): 273-284.

Markowitz LE, Hariri S, Lin C, Dunne EF, Steinau M, McQuillan G, Unger ER (2013) Reduction in human papillomavirus (HPV) prevalence among young women following HPV vaccine introduction in the United States, National Health and Nutrition Examination Surveys, 2003-2010. J Infect Dis 208(3): 385-393.

McCrory DC, Matchar DB, Bastian L, Datta S, Hasselblad V, Hickey J, Myers E, Nanda K (1999) Evaluation of Cervical Cytology, Summary. Evidence Report/Technology Assessment. Number 5, pp 1-6. Agency for Healthcare Research and Quality: Rockville, MD.

Moscicki AB, Shiboski S, Broering J, Powell K, Clayton L, Jay N, Darragh TM, Brescia R, Kanowitz S, Miller SB, Stone J, Hanson E, Palefsky J (1998) The natural history of human papillomavirus infection as measured by repeated DNA testing in adolescent and young women. J Pediatr 132(2): $277-284$.

Myers ER, McCrory DC, Nanda K, Bastian L, Matchar DB (2000) Mathematical model for the natural history of human papillomavirus infection and cervical carcinogenesis. Am J Epidemiol 151(12): $1158-1171$.

National Center for Health Statistics (1992) Vital Statistics of the United States, 1988. Public Health Service: Washington.

Robberstad B (2005) QALYs vs DALYs vs LYs gained: what are the differences, and what difference do they make for health care priority setting? Norsk Epidemiologi 15(2): 9.

Sloan F (1995) Valuing Health Care: Costs, Benefits, and Effectiveness of Pharmaceuticals and Other Medical Technologies. Cambridge University Press: New York and Melbourne.

Smith JS, Lindsay L, Hoots B, Keys J, Franceschi S, Winer R, Clifford GM (2007) Human papillomavirus type distribution in invasive cervical cancer and high-grade cervical lesions: a meta-analysis update. Int J Cancer 121(3): 621-632.

Sun XR, Wang J, Garner D, Palcic B (2005) Detection of cervical cancer and high grade neoplastic lesions by a combination of liquid-based sampling preparation and DNA measurements using automated image cytometry. Cell Oncol 27(1): 33-41.

Susini T, Olivieri S, Molino C, Amunni G, Rapi S, Taddei G, Scarselli G (2011) DNA ploidy is stronger than lymph node metastasis as prognostic factor in cervical carcinoma: 10-year results of a prospective study. Int J Gynecol Cancer 21(4): 678-684.

Syrjanen K, Kataja V, Yliskoski M, Chang F, Syrjanen S, Saarikoski S (1992) Natural history of cervical human papillomavirus lesions does not substantiate the biologic relevance of the Bethesda System. Obstet Gynecol 79(5 (Pt 1)): 675-682.

Tabbara SO, Sidawy MK (1996) Evaluation of the $10 \%$ rescreen of negative gynecologic smears as a quality assurance measure. Diagn Cytopathol 14(1): 84-86.

The Council of Economic Advisers (2013) Economic Report of the President. pp 395-395. U.S. Government Printing Office: Washington.

Tong H, Shen R, Wang Z, Kan Y, Wang Y, Li F, Wang F, Yang J, Guo X (2009) DNA ploidy cytometry testing for cervical cancer screening in China (DNACIC Trial): a prospective randomized, controlled trial. Clin Cancer Res 15(20): 6438-6445.

Weinstein MC (2008) How much are Americans willing to pay for a qualityadjusted life year? Med Care 46(4): 343-345.

(2) (i) (2) This work is licensed under the Creative Commons Attribution-Non-Commercial-Share Alike 4.0 International License. To view a copy of this license, visit http:// creativecommons.org/licenses/by-nc-sa/4.0/ 